\title{
La influencia del cluster vitivinícola en el desarrollo local: el caso de Mendoza (Argentina) y Serra Gaucha (Brasil)
}

María Verónica Alderete ${ }^{1}$

Resumo: A teoria do desenvolvimento endógeno estabelece que o desenvolvimento económico das regiões deve apoiar-se nos recursos existentes em seus territórios com a finalidade de melhorar o bem-estar local. Em Argentina, o cluster vitivinícola de Mendoza presenta características que o converte numa fonte de desenvolvimento local. Por sua parte, a indústria vitivinícola do Brasil, ainda que não seja um jogador importante no mercado internacional de vinho ha mostrado signos de progresso recentemente. O objetivo deste trabalho consiste em comparar as regiões vitivinícolas de Mendoza (Argentina) e de Rio grande do Sul (Brasil) em quanto ao sistema produtivo vitivinícola, o rol das indicações geográficas e sua incidência sob o desenvolvimento territorial.

Palabras claves: clúster vitivinícola; desenvolvimiento territorial; indicações geográficas.

JEL: L66, R11, Q13. 


\title{
The influence of the wine cluster in local development: the case of Mendoza (Argentina) and Serra Gaucha (Brazil)
}

\begin{abstract}
The Endogenous Development Theory explains that economic development of regions must be based on their existent territorial resources to improve local welfare. In Argentine, Mendoza's wine cluster presents some characteristics that turn it into local development source. On the other side, the Brazilian wine industry, while not being a key player at the international wine market, has recently shown signs of progress. The objective of this paper is to compare the wine productive systems from Mendoza (Argentine) and Rio Grande Do Sul (Brazil) in terms of their production systems, the role of geographic indications and their incidence on territorial development.
\end{abstract}

Keywords: wine cluster; territorial development; geographic indications.

JEL: L66, R11, Q13.

\section{Introducción}

Durante las últimas décadas, se observa la recuperación de los espacios locales y regionales como ámbitos específicos en los que los actores pueden construir su propia identidad estratégica para enfrentar el proceso de globalización y el nuevo contexto competitivo. En este marco, la literatura reciente hace hincapié en el fenómeno de formación de redes y a los factores locales/ regionales que contribuyen a la conformación de ámbitos de cooperación empresarial.

La teoría del desarrollo endógeno establece que el desarrollo económico de las regiones debe apoyarse en los recursos existentes en su territorio con el fin de lograr mejores niveles de vida para la población local. Así las estrategias de desarrollo económico local tienen como prioridad el desarrollo de territorios con capacidad competitiva, planteándose como objetivos: el desarrollo y reestructuración del sistema productivo, el aumento del empleo, y el mejoramiento del nivel de vida de la población local (Vázquez Barquero, 1986).

Este nuevo paradigma tiene como variable fundamental el territorio, entendido como una agrupación de relaciones sociales, culturales, productivas, económicas y políticas. Es ahí donde ocurren las reestructuraciones a fondo y se establecen encadenamientos productivos importantes que mediante estrategias de desarrollo económico local pueden reforzarse y convertirse en fuente de ventaja competitiva, a través de la utilización de los recursos potenciales del territorio (Garofoli, 1995; Padilla, 1996). 
Las ventajas competitivas ya no se basan únicamente en insumos baratos y en economías de escala. Por el contrario, está cada vez asociada a la capacidad de las empresas en generar conocimiento e innovación que proporcionen una posición favorable frente a la competencia. Desde esta perspectiva, la realización de un producto diferenciado puede representar una oportunidad de construir un puente para nichos de mercados más exigentes. En este sentido, las indicaciones geográficas son estrategias que posibilitan agregar valor a los productos de origen agrícola. Aún con sus particularidades, es preciso que los lugares estén en contacto con el contexto internacional.

En Argentina, no se han desarrollado las condiciones para que el territorio desempeñe un rol de estímulo y creación de externalidades para el colectivo industrial y social (Boscherini, F. y Poma, L., 2000).” Sin embargo, el cluster vitivinícola de Mendoza presenta características que lo convierten en una excepción. Mendoza posee aproximadamente el 70\% de los viñedos finos de Argentina. Esto explica la mayor participación relativa de la provincia en relación al resto del país.

El mercado de vinos se divide, de una manera general, en dos grandes segmentos: de los vinos comunes, elaborados con uvas no viníferas; y el de los vinos finos, producidos a partir de variedades de uvas viníferas. Sin embargo, dentro de los vinos finos se encuentra la categoría de los vinos que son producidas en regiones geográficamente delimitadas y que, justamente por ese motivo, ostentan los sellos de indicaciones geográficas (Lemos Jeziorny, 2009). Es importante el papel que cumplen las IG como creadoras de competitividad y promotoras del desarrollo local.

Según datos de EMBRAPA Uva e Vinho, la producción de vino en Brasil se concentra en un $90 \%$ en el estado de Río Grande do Sul, que le otorga al producto una identidad regionalista al vino. Actualmente, Brasil no es un jugador importante en el mercado internacional de vino y es difícil para ellos competir con otros países como Chile y Argentina que producen su producto con calidad similar y a menores precios (Nierop, 2010). La región de Rio Grande Do Sul desempeña sóla un papel semejante al de Mendoza y San Juan en Argentina. En la región de Serra Gaucha, la vitivinicultura abarca un área de 27 mil hectáreas y 620 vinificadoras, de acuerdo con el IBRAVIN (Instituto Brasileiro do Vinho). El sistema agroalimentario brasilero es un caso paradigmático por la propia coexistencia de dos modelos agroalimentarios altamente relacionados y competitivos. De un lado, un conjunto emergente de mercados de calidades específicas; de otro, un mercado de commodities que comienzan a considerar el creciente desarrollo de una economía de calidades. Serra Gaucha posee una aglomeración de un número significativo de empresas actuando en diferentes cadenas productivas relacionadas con la producción de vino, con una participación significativa en el número de puestos de trabajo, facturación, mercado, potencial de crecimiento, diversificación, entre otros aspectos (GOLLO, 2006). 
Con la mundialización del mercado vinícola en el mundo, cada vez más las Indicaciones Geográficas (IG) están incorporadas a la dinámica industrial y comercial de modo que el componente de enraizamiento territorial de los productos convive con los marcos institucionales de las cadenas de valor globales (Niederle e Vitrolles, 2010). El objetivo de este trabajo consiste en comparar los clusters vitivinícolas de Mendoza (Argentina) y Serra Gaúcha (Brasil) desde una perspectiva de desarrollo local. Con este fin se plantea en primer lugar el marco teórico de desarrollo local, introduciendo la noción de indicaciones geográficas. Asimismo, se describen brevemente la estructura de los clusters vitivinícolas estudiados para posteriormente describir su desempeño en términos de algunos indicadores de la actividad vitivinícola. A su vez se plantean las indicaciones geográficas alcanzadas por el sector en cada región, y la importancia de las instituciones para su desarrol lo.

\section{Desarrollo local}

La "teoría de desarrollo local" consiste en un modelo de desarrollo que no se basa simplemente en mensurar o medir las variables económicas, como tasas de interés, salarios, inflación y sus posibles impactos regionales. Con el objetivo de tratar las potencialidades de una región geográfica determinada, se debe tener en consideración, sobretodo, los recursos naturales existentes, la vocación y competencia de la mano de obra de la comunidad y factores socio-culturales, entre los cuales se destacan la cooperación entre empresas, tradiciones, costumbres, etc.

El reconocimiento de la importancia de las redes en la competitividad de los territorios es observada en las investigaciones socioeconómicas: la cooperación inter-firma permite la construcción de sistemas de negocios que buscan entornos competitivos e innovativos. Este proceso tiene lugar tras la adquisición de ventajas resultantes de ciertas externalidades territoriales derivadas de la aglomeración, y también, tomando ventaja de la tradición de negocios territorial (Narvaez et al, 2008; Caravaca et al, 2003).

Vázquez Barquero (1999) se refiere a un desarrollo construido por la economía según la escuela de crecimiento endógeno. Algunas de las conclusiones que esta perspectiva considera han sido incorporadas en teorías más recientes del desarrollo endógeno. La perspectiva de crecimiento y la del desarrollo endógeno comparten la visión de que los sistemas productivos consisten de un grupo de factores materiales e inmateriales que permiten a las economías locales y regionales adoptar trayectorias diferentes hacia el crecimiento para el desarrollo, y por lo tanto, existe un espacio para la política regional e industrial

La competitividad de las especializaciones productivas y la variedad de senderos evolutivos que un sistema productivo o un distrito pueden emprender 
dependen de la capacidad que la estructura interna tiene para responder a los estímulos externos sin perder su identidad. La plasticidad de la estructura interna del sistema local se refiere al concepto de territorio como integrador versátil. El concepto de desarrollo local como acoplamiento estructural estimula el análisis sobre la capacidad que la organización territorial tiene para seguir desempeñando, de manera evolutiva, la función de generación de competencias específicas y lugar de relaciones sociales. Esto significa analizar al distrito industrial bajo tres perspectivas: como sistema productivo que reacciona, a través de ajustes e innovaciones internas, a los cambios en el escenario competitivo; como contexto de creación e intercambio de conocimiento; y como conjunto de instituciones de (auto) reglamentación social (Coró, 2000).

$\mathrm{Al}$ referirnos al desarrollo local y territorial debemos establecer la importancia de estas cuatro dimensiones (Gallicchio, 2004): Económica: relacionada con la creación, acumulación y distribución de la riqueza; Social y Cultural: implica calidad de vida, equidad e integración social; Ambiental: se refiere a los recursos naturales y a la sustentabilidad de los modelos de mediano y largo plazo y Política: governancia territorial, proyecto colectivo independiente y sustentable.

El desarrollo local es un proceso orientado por la acción de diferentes agentes y raramente emerge espontáneamente (Barreiro Cavestany, 2000). Esto requiere de una forma compleja de governancia, que involucre actores claves preocupados por el desarrollo de la región y sectores productivos seleccionados. En este sentido, los proyectos de desarrollo local involucran un gran número de actores institucionales y empresas, los cuales frecuentemente no poseen mecanismos de coordinación preexistentes, y están inevitablemente bloqueados por patrones de interacción históricos.

\subsection{Indicaciones geográficas y Desarrollo local}

Lemos Jeziorny (2009) considera ciertos elementos relevantes para el desarrollo local, destacándose: i) capacidad organizativa por parte de los actores locales, ii) capacidad de difundir conocimiento, información e innovaciones; iii) facilidad de articularse en torno de redes. Las ideas de autores como Reis (2007), Barquero (1999; 2001), Cassiolato e Lastres (2003), entre otros avalan esta idea.

En este sentido, las IG son relevantes para el desarrollo local, ya que no sólo agrega más valor al vino, al aumentar la calidad del producto, y reducir la incertidumbre para el consumidor sino que pasa los límites estrictos de la vitivinicultura para ganar importancia en un proyecto de desarrollo de base territorial. Esto ocurre debido a que a la actividad vitivinícola se agrega el enoturismo. 
Al cualificar activos intangibles que son de difícil transmisión hacia otros territorios, las IG pueden ser conceptualmente percibidas como un catalizador de procesos de desarrollo territorial/endógeno (Niederle e Vitrolles, 2010). Las IG permiten, por lo tanto, que un grupo de productores que tenga el mismo territorio como sustrato de su existencia, promuevan sus productos colectivamente, con fuerte apego en los atributos locales, como técnicas agronómicas y recursos naturales que son típicos del lugar (Lemos Jeziorny, 2009).

Nierdele y Vitrolles (2010) consideran que las IG han permitido la valorización de los territorios y de su identidad cultural. Al mismo tiempo, existe un proceso de apropiación sectorial por medio del cual éste es ajustado de modo de servir como un catalizador de innovaciones técnicas y organizacionales, las cuales son esenciales para lograr la competitividad del sector. Las IG pueden promover innovaciones en virtud del fuerte encuadramiento normativo al cual son sometidos los productores.

Varios autores (Vandecandelaere et al, 2009; Allaire et al, 2007) han demostrado que existe mucha heterogeneidad en los sistemas de IG al involucrar diferentes actores, mecanismos de gobernancia, formatos institucionales de mercados, políticas de soporte, etc., y por lo tanto, diferentes impactos sobre la dinámica del desarrollo de los territorios involucrados. Las indicaciones geográficas ponen en evidencia el modo como este instrumento implica una valorización de las tradiciones, costumbres, saberes, prácticas y otros bienes inmateriales asociados a una identidad territorial y un origen geográfico (Bérard e Marchenay, 2008; Cerdan et al, 2009).

Para Tonietto (1992) la principal innovación surge de un cambio en la autonomía de gestión. Si hasta entonces cada productor generaba su propio negocio aisladamente y tomaba sus decisiones en conformidad con las oportunidades que le surgían, a partir de su opción por integrarse a una estrategia de IG, sus decisiones pasan a ser de carácter colectivo. Las decisiones individuales necesitan respetar un reglamento, válido para todos. La producción con base en la IG toma como premisa el territorio, a diferencia de una producción convencional.

\section{Estructura del cluster vitivinícola}

3.1 Mendoza

La situación del complejo vitivinícola mendocino constituye un ejemplo regional de larga data, cuyo nodo articulador se encuentra en la etapa de procesamiento industrial y en el que, históricamente, los pequeños productores familiares tuvieron una importante participación en la elaboración de 
vino común de mesa ${ }^{1}$.

Al tratarse de una compleja actividad que incluye desde la plantación de vid, la cosecha de la uva, la comercialización de ésta, la elaboración de vinos y derivados de la uva, su fraccionamiento y comercialización, involucra tanto al sector agropecuario como al sector de industrias manufactureras.

La cadena o circuito productivo agroindustrial vitivinícola consta de un número limitado de eslabones, cuyo origen es la producción de uva, y que se ramifican, según el uso dado a dicha producción, en tres eslabonamientos principales: consumo en fresco, elaboración de pasas e industrialización, siendo esta última la principal y más importante destinataria y demandante de la misma. Siguiendo el encadenamiento industrial, se presentan dos subcadenas de relevancia: en primer lugar la elaboración de vinos o mostos, y en segundo término la producción de jugos de uva (cuya utilización sirve como endulzante o para cortes de jugos de fruta). La característica más sobresaliente es la sobre-dimensión que adquiere en dicha cadena la producción vínica.

En términos productivos el sector vinícola de Mendoza está dispuesto espacialmente en la forma de clusters. Los clusters vinícolas de Mendoza presentan una conformación expresa conforme el Gráfico 1.

En la base de la producción se encuentran los viñedos que proveen a las bodegas de materia prima básica, los cuales disponen de una red de proveedores de insumos: fertilizantes, máquinas e implementos para cosecha, equipos de irrigación, entre otros.

Por otro parte, encontramos las bodegas que se benefician de las uvas provistas para la producción de vino. Esta producción requiere una serie de insumos. Para la elaboración de vinos, se encuentran las industrias proveedoras de equipos para la elaboración de vinos, empresas proveedoras de tanques, barriles, vidrios, etc; así como se observa la presencia de empresas prestadoras de servicios de marketing y software. Se estima que existen aproximadamente 200 empresas proveedoras de bienes y servicios para los clusters vinícolas (IIRSA, 2006)

Además de las empresas proveedoras, existen diversas instituciones que prestan apoyo a las actividades productivas de uva y vino como los centros de investigación y desarrollo, universidades (se encuentra la Universidad Nacional de Cuyo, la sede regional de la Universidad Tecnológica Regional y la Universidad Agustín Maza, Guaymallén, Mendoza), asociaciones empresariales y gremiales, instituciones gubernamentales de apoyo y regulación (Instituto Nacional de Vitivinicultura INV, COVIAR Corporación Vitivinícola Argentina, ProMendoza), así como instituciones financieras. Asimismo, se encuentran las empresas responsables por las redes de distribución tanto

1 Hasta el año 2003, el tipo de vino se clasificaba en vino de mesa, fino y otros. A partir de la liberación de los vinos nuevos (Res INV No12/04) se pone en marcha el proceso de descategorización de los vinos, debiéndose indicar solamente con la palabra vino. 
en el territorio nacional como en otros mercados externos. Estas empresas demandan servicios externos para la provisión de servicios de transporte y logística. Asimismo, las actividades vinícolas y vitícolas han logrado una integración virtuosa con el sector comercial y turístico de la provincia. Existen diferentes rutas turísticas creadas que integran la producción de vino con los sectores hoteleros, comercios, tiendas, etc.

\subsection{Serra Gaucha}

Serra Gaúcha es el principal polo vitivinícola de Brasil, ubicado en el Nordeste de Rio Grande Do Sul. Los productores de uva y vino presentan la conformación de un APL, en una etapa avanzada de evolución. En los años 90 se produjo la transformación de muchos viticultores en vitivinicultores. Tuvo origen la integración vertical en la producción y comercialización. El cluster tiene garantizada la viabilidad y el fortalecimiento de la inserción internacional de diversas industrias de vinos de RGS.

El centro del cluster está formado por productores de vid y productores de vino, alrededor de los cuales se encuentran los proveedores de insumos para la producción, maquinarias y equipos, así como instituciones locales, regionales y nacionales (instituciones gubernamentales, asociaciones empresariales, instituciones de crédito, educación e investigación) que negocian directa o indirectamente con la uva y el vino.

Se trata de una viticultura de pequeñas propiedades, con media de 15 hectáreas, siendo de éstas un 40\% a 60\% de área útil y 2,3 hectáreas de viñedos, poco mecanizada debido a la topografía accidentada, donde predomina el uso de la mano de obra familiar, cada propiedad dispone en promedio de 4 personas. Entre los cultivares tintos de destacan Cabernet Sauvignon, Merlot, Cabernet Franc y Tannat. Por su parte, las empresas vinícolas tienden a la integración vertical para garantizar la materia prima necesaria para la elaboración de vinos finos, debido a las condiciones climáticas a veces adversas de Serra Gaucha, que causan baja rentabilidad de los viñedos, al reducir la productividad física, la calidad de la uva y aumentar el uso intensivo de insumos. En un nivel superior se encuentra el gobierno y las instituciones profesionales y comerciales, que son socios en el control, regulación, coordinación y promoción de las actividades relacionadas con el negocio de la uva y el vino. En un nivel inferior, se encuentran las organizaciones de educación e investigación, incluyendo universidades involucradas con la vid y la investigación de vinos (UCS, UFRGS, UFSM, Unisinos), la Escuela Tecnológica especializada en la viticultura y la enología (CEFET-BG), un instituto federal de investigación de vid y vino (EMBRAPA) y dos instituciones agropecuarias estatales, una focalizada en la investigación (FEPAGRO) y la otra en la asistencia técnica (EMATER). 


\section{GRÁFICO 1. MODELO DE CLUSTER DEL VINO EN MENDOZA}

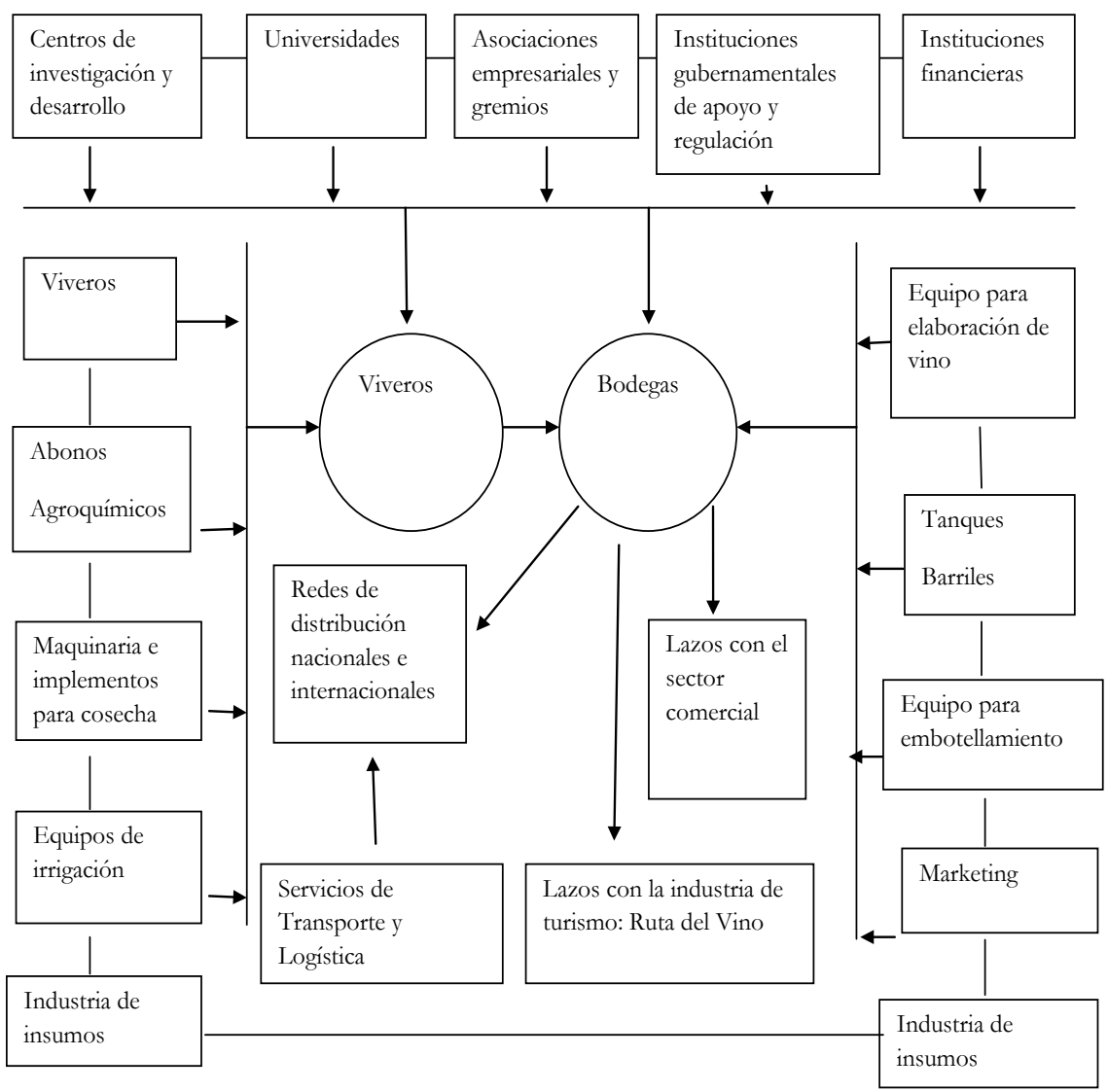

Fuente: IIRSA, Iniciativa para la Integración de la Infraestructura Regional Suramericana

Este cluster interactúa con otros tres clusters de la región: el cluster agrícola y de turismo, alimentos y restaurantes, aumentando la importancia del enoturismo (Gráfico 2). El cluster contiene dos tipos de redes de productores de vinos que son de gran importancia para su desarrollo futuro: asociaciones creadas con el objetivo de desarrollar subregiones particulares dentro del cluster y un consorcio de exportación, llamado Wines From Brazil ubicado en Bento Goncalves, RS. Este consorcio consiste en un esfuerzo colectivo para ubicar a Brasil en el mercado internacional. 
GRÁFICO 2. MODELO DE CLUSTER DEL VINO EN SERRA GAUCHA

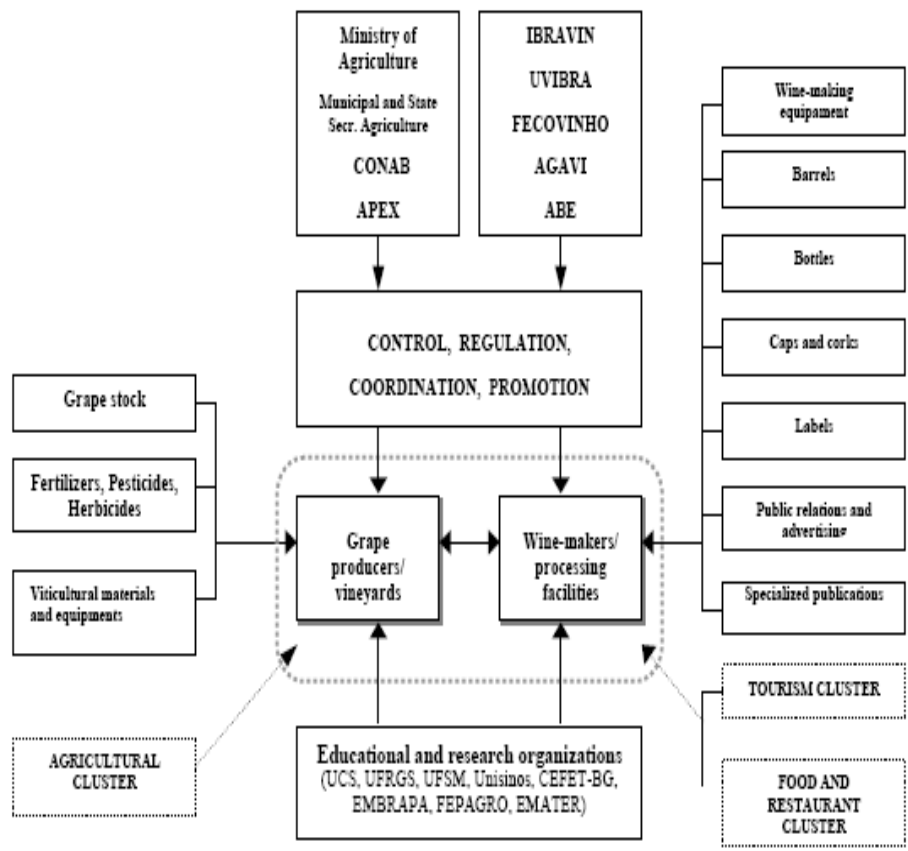

Fuente: Fensterseifer (2006).

\section{Indicadores económicos: comparación}

El producto Bruto Geográfico se compone de distintos sectores de actividad. La actividad vitivinícola se encuentra contabilizada tanto en el Sector agropecuario, a través de la actividad vitícola (producción de uvas) como en la Industria Manufacturera (elaboración de vino, mosto y otros productos). En términos desagregados, el 22,59\% del producto provincial mendocino proviene del sector Comercio, Restaurantes y Hoteles. A esta actividad, le siguen en orden de importancia Servicios Comunales, Sociales y Personales con el $16,89 \%$ e Industrias manufactureras con el 15,82\%. La actividad industrial que más influencia tiene en el PBG de la Industria Manufacturera provincial es la actividad de Refinerías de petróleo y petroquímica, en segundo lugar se encuentra la actividad de Elaboración de bebidas (mayoritariamente actividad vitivinícola). La vitivinicultura constituye para Mendoza una de sus principales actividades económicas debido a que ha generado en promedio para el período 1991-2002 alrededor del 8\% del total del valor agregado bruto del PBG (Gráfico 3). 
GRÁFICO 3. EVOLUCIÓN DEL PRODUCTO BRUTO GEOGRÁFICO DE LA PCIA. MENDOZA

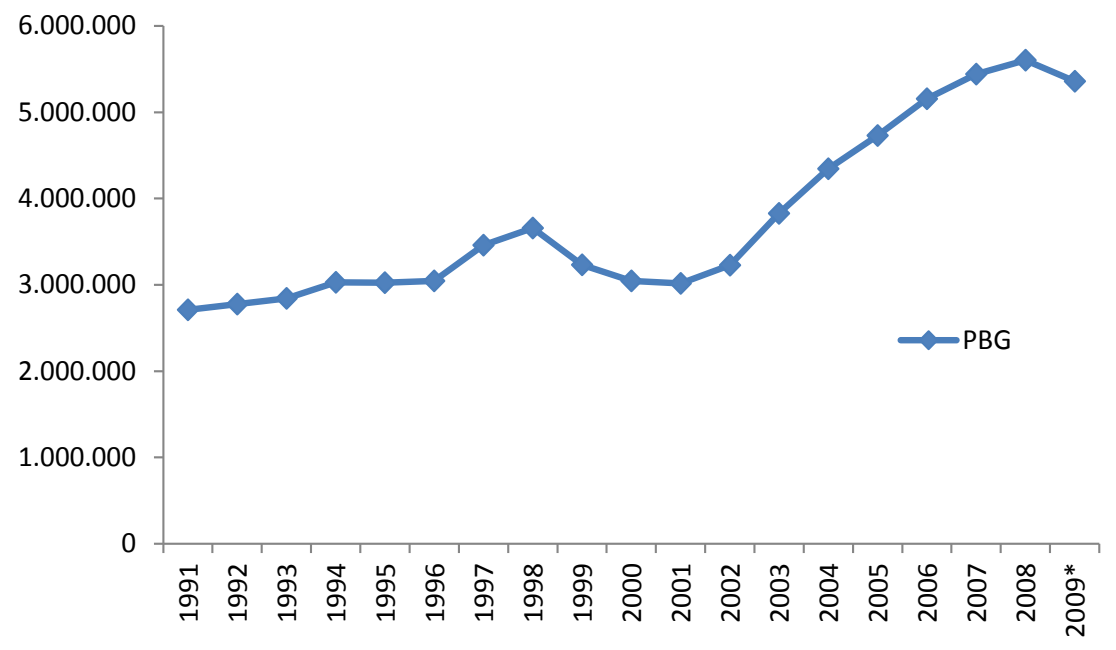

Fuente: DEIE

La participación relativa de la Industria Manufacturera es superior a la participación del sector Agropecuario en el PBG (Gráfico 4). Según datos de 2009, del Total del PBG, el Sector Vitivinícola (Agropecuario (Uva) más Industrial (Vino y Mosto)) representa un 18\% del Total del PBG.

En Serra Gaúcha (Gráfico 5) también se observa una evolución positiva del PBI durante los últimos años, con un incremento del 72,28\% del PBI en el período 2003-2008. En cuanto a la composición del producto en la región es posible observar una participación de la industria sobre el producto superior al sector agropecuario en alrededor de un 30 \% durante los últimos años. 
GRÁFICO 4. PARTICIPACIÓN DEL SECTOR AGROPECUARIO Y MANUFACTURERO EN EL PBG MENDOZA

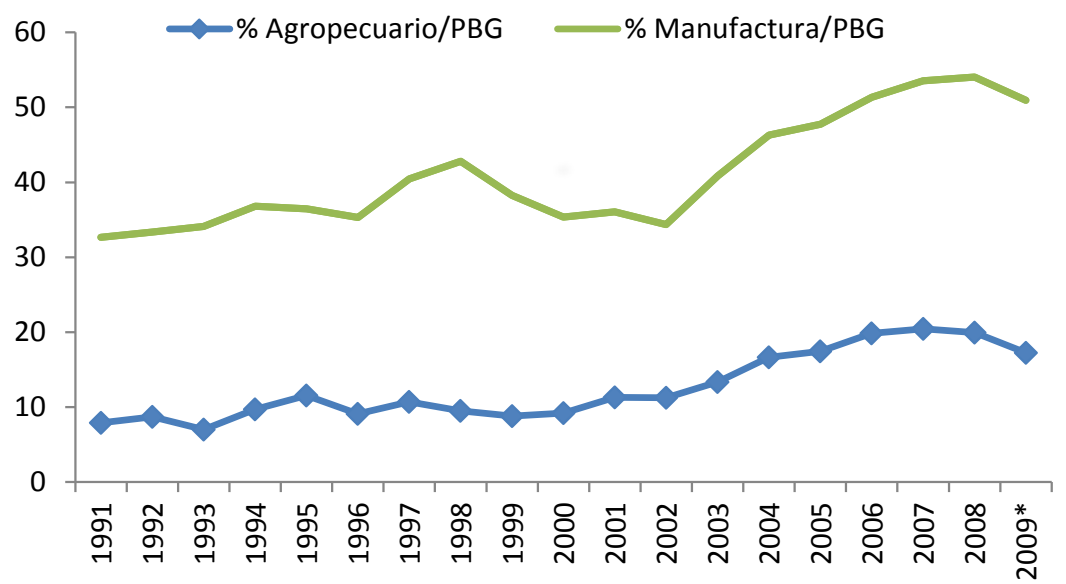

Fuente: Elaboración propia según datos DEIE.

\section{GRÁFICO 5. EVOLUCIÓN PBI SERRA GAÚCHA}

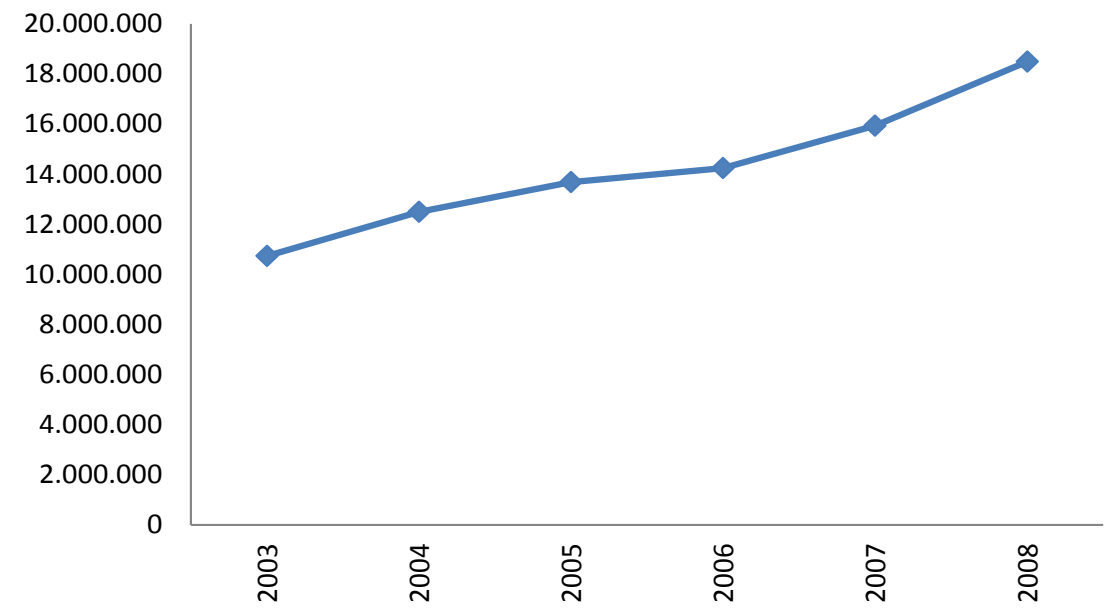

Fuente: Elaboración propia según datos IBGE. 


\section{GRÁFICO 6 PARTICIPACIÓN SECTORES INDUSTRIAL Y AGROPECUARIO EN EL PBI SERRA GAÚCHA}

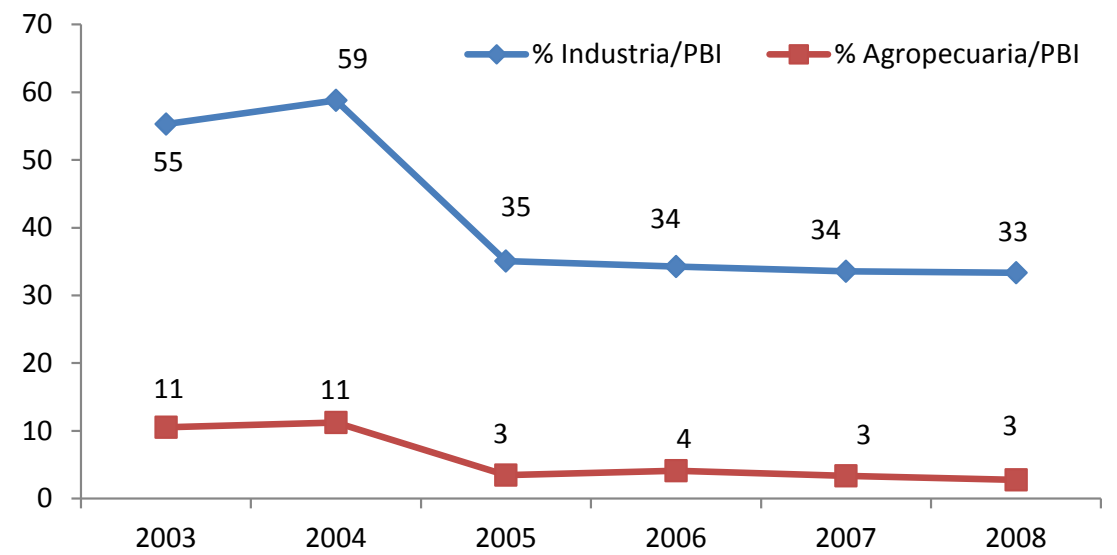

Fuente: Elaboración propia según datos IBGE.

\section{GRÁFICO 7. PRODUCCIÓN DE UVAS EN VOLUMEN}

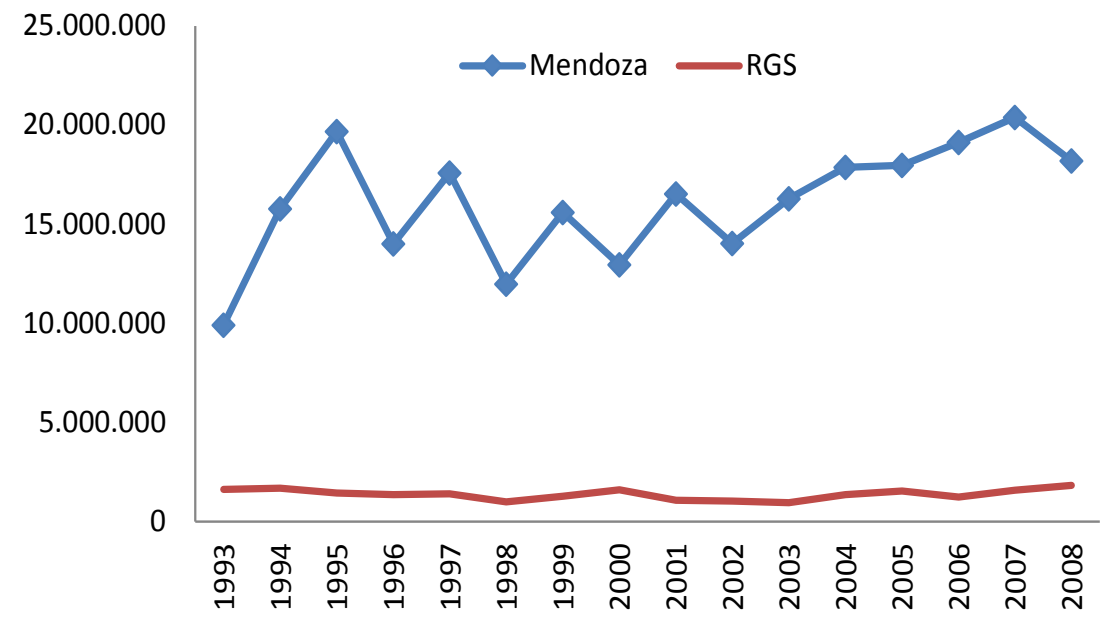

Fuente: Elaboración propia según datos INV y EMBRAPA UVA e VINHO.

En Rio Grande Do $\mathrm{Sul}^{2}$, el cultivo o producción de viníferas representa el 20\% de la producción total de uvas, en promedio. Este porcentaje relativamente bajo es uno de los posibles condicionantes para una futura expansión de la producción brasilera de vinos. En Mendoza, se destaca el predominio de la producción de uvas para vinificar con respecto a los otros destinos (uva fresca,

2 Los indicadores vitivinícolas corresponden a Rio Grande Do Sul. Los centros de información estadística de Brasil no disponen de esta información a nivel de municipios, para poder calcular a nivel de la región Serra Gaucha. De todos modos, RGS representa el 90\% de la producción de vinos nacional. 
para pasas). En 2008, el monto total de uvas para procesar creció en 11,13\% con respecto a 2007, mientras que la producción de uvas frescas disminuyó (Gráfico 7).

Actualmente, Brasil ocupa el puesto número 16 en el ranking mundial como productor de vinos. Del total de los productos industrializados, el $77 \%$ está conformado por vinos de mesa y el $9 \%$, jugo de uva, ambos elaborados a partir de uvas de origen americano y otras variedades híbridas (COVIAR, 2009). Se puede observar (Gráfico 8) una evolución en la producción de vinos a lo largo del período analizado similar a la producción de uvas viníferas (Gráfico 7) entre las regiones comparadas.

\section{GRÁFICO 8. ELABORACIÓN VINO (HLTS)}

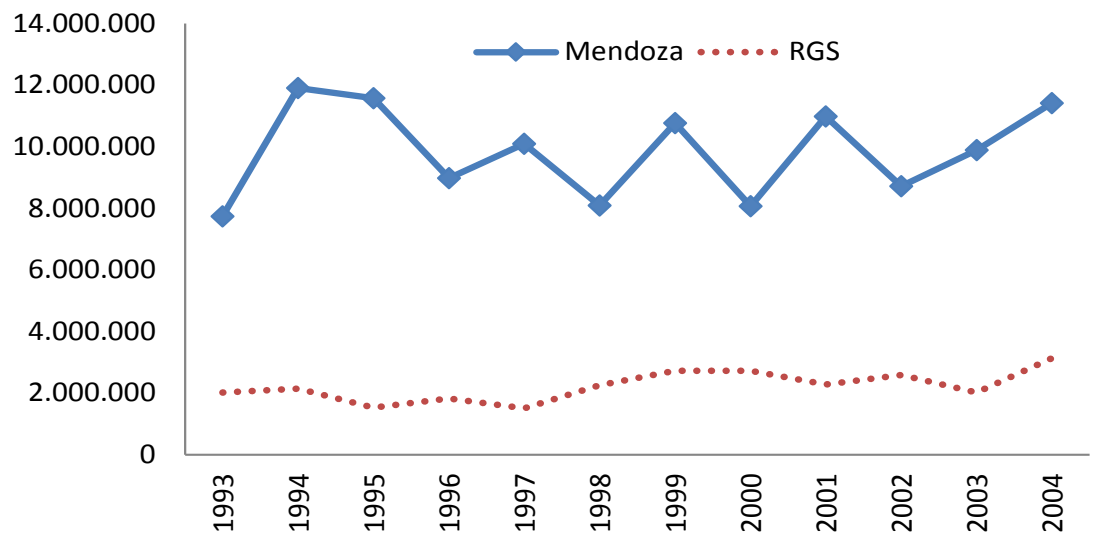

Fuente: Elaboración propia según datos INV y EMBRAPA UVA e VINHO.

En Mendoza, la producción de vino y otros productos vínicos mantiene un promedio de entre 11 y 12 millones de hectolitros, representando aproximadamente entre el 68\% y el 70\% de la producción nacional. El vino fino (Gráfico 9) producido en Mendoza ha mostrado un aumento a lo largo del período, con periodos crecientes como en los noventa y a partir de 2003. 
GRÁFICO 9. PRODUCCIÓN DE VINO (HLTS)

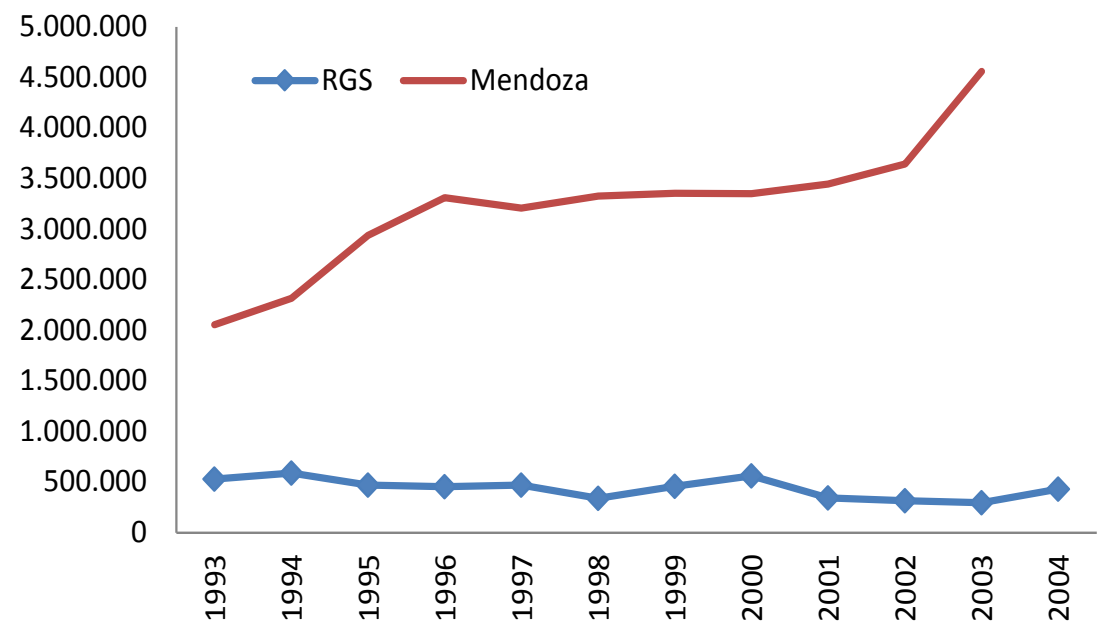

Fuente: Elaboración propia según datos INV y EMBRAPA UVA e VINHO.

En Rio Grande Do Sul, desde mediados de los noventa hasta mediados del 2000 se observa una disminución de la producción de vinos finos, hay un predominio claro en la elaboración de vinos comunes. Recién a partir de 1999, comienza la elaboración de vinos espumantes. La producción de espumantes paso de 7 mil litros en 1999 a 970 mil litros en 2005. Los vinos comunes son elaborados principalmente con uvas americanas e híbridas, mientras que los vinos finos son producidos a partir de Vitis Viníferas (variedades más nobles).

A diferencia del mercado mendocino, donde se calcula que se consumen 30 litros de vinos per cápita anuales promedio, el consumidor brasilero presenta un bajo consumo de vino per cápita. Según una proyección de IBRAVIN (Instituto Brasileiro do Vinho), el consumo alcanzaba los 1,8 litros per cápita al año. En el 2009, Brasil posee un mercado pequeño con una ingesta de vino promedio de dos litros anuales por habitante.

Hace 9 años que se exportan los vinos brasileros, y en la actualidad, las ventas en el mercado externo no llegan al 1\% del total de la producción, liderando el vino espumante fino como producto exportado. En términos de inserción internacional del vino brasilero, no sólo existen condiciones globales desfavorables, sino también condiciones domésticas adversas tales como: bajo nivel de consumo per cápita (1,8 litros frente a los 30 litros de Argentina y Uruguay en promedio), ausencia de la cultura del vino en la alimentación, falta de imagen como país productor de vino, baja importancia del sector para la economía nacional (aunque sea económicamente importante para Rio Grande Do Sul donde se encuentra concentrada la producción) y una alta incidencia impositiva (representan los impuestos alrededor del $42 \%$ del precio al consumidor, comparado con aproximadamente la mitad en Argentina y 
aún menos en Chile, actualmente los dos grandes exportadores de vino hacia Brasil) (Fensterseifer, 2006).

Según la Organización Internacional de la Viña y el Vino (OIV), Argentina es el primer productor vitivinícola de América del Sur, el quinto productor vitivinícola del mundo, concentrando aproximadamente el $6 \%$ de la producción mundial, y el noveno exportador mundial (3,3\%). Sin embargo, la República Argentina no ha podido lograr aún una alta participación en las exportaciones mundiales, principalmente debido al alto consumo interno, similar al de los países europeos.

GRÁFICO 10. EXPORTACIONES VINO DE MESA

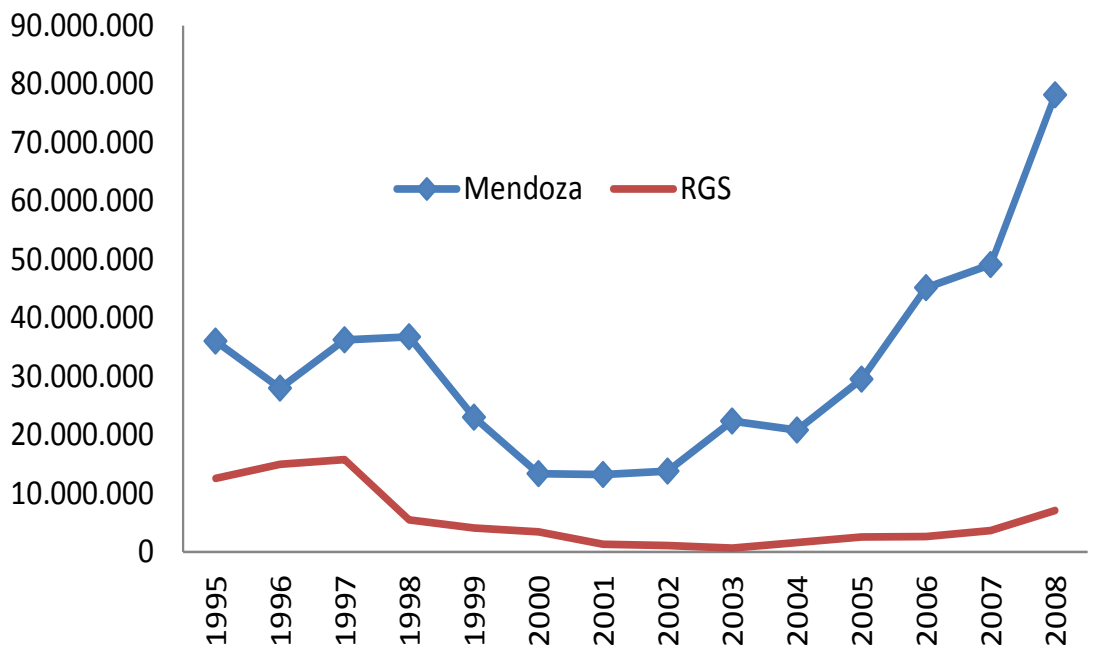

Fuente: Elaboración propia según datos INV y EMBRAPA UVA e VINHO.

Mendoza exporta anualmente productos por un valor aproximado de 220 millones de dólares, cuyo mayor porcentaje proviene de las exportaciones de vinos finos (Gráfico 10). Argentina es reconocida como un país productor de Malbecs bien refinados, y los de Mendoza son considerados los mejores del mundo. Las exportaciones en envases menores a 2 litros han tenido una participación superior a los vinos en envase mayor a dos litros (en general vinos de mesa). Actualmente, la participación de los envases mayores es inferior a la obtenida1o años atrás. Es en las exportaciones de vino fraccionado donde radica el dinamismo y crecimiento sostenido de la vitivinicultura (Informe Provincia de Mendoza 2009). 


\section{Impacto de las indicaciones geográficas y el rol de las instituciones}

\subsection{Brasil}

En Brasil, la implementación de las indicaciones Geográficas (IG) se concretizó con el advenimiento de la Ley 9279 "Ley de Propiedad Industrial" el 14 de mayo de 1996. Con esta nueva ley, la pirámide de las IG para vinos de calidad producidos en regiones delimitadas es la siguiente:

\section{GRÁFICO 11. PIRÁMIDE DE LAS INDICACIONES GEOGRÁFICAS}

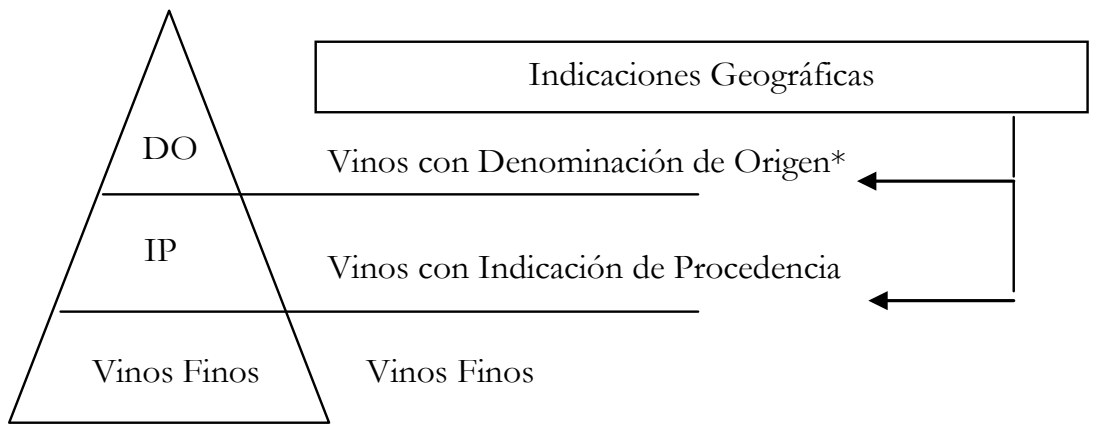

Fuente: Tonietto y Mello, 2001 * La denominación de origen es un tipo especial de indicación geográfica, que se aplica a productos que poseen una calidad específica derivada exclusiva o esencialmente del medio geográfico, incluyendo los factores naturales y humanos intervinientes en la elaboración, que debe realizarse en forma total y completa en dicho ámbito. El concepto de indicación geográfica engloba a las denominaciones de origen.

En Noviembre de 2002, se reconoció la denominación "Vale Dos Vinhedos" como Indicación Geográfica- Indicación de Procedencia (IP) y tiene como titular a APROVALE (Associação dos Produtores de Vinhos Finos do Vale dos Vinhedos). Además,la región posee más de cinco proyectos de certificación en curso, lo que la convierte en una especie de knowledge cluster (Giulani, 2007). Según Tonietto (2002), la trayectoria histórica de Serra Gaúcha posibilitó la visión de una macroidentidad con vistas a la organización de una indicación geográfica.

En la región de Rio Grande Do Sul, así como en la región Nordeste (Pernambuco e bahía) se observa el direccionamiento de instituciones existentes (APROVALE, Asprovinho, Valexport) así como de líderes productivos de las regiones con potencialidad para una futura organización asociativa (Campanha, Serra do Sudoeste, São Joaquim) para la restructuración y la tutela de las indicaciones geográficas de vinos. Se observa un direccionamiento hacia potenciales IG futuras, Actualmente, EMBRAPA Uva e Vinho apoya otros 
proyectos de consolidación de IG en Rio Grande Do Sul y en Santa Catarina incluyendo: a) Serra Gaúcha, con subregiones como Pinto Bandeira, Flores da Cunha-Nova Pádua, entre otras; b) Campanha; c) Serra Do Sudoeste; d) Vale do Submedio São Francisco.

La determinación de las Indicaciones Geográficas (IG) es realizado en conjunto con el sector privado, es decir, de forma integrada se busca sinergia entre las acciones públicas y las privadas. Los productores tienen una demanda específica y EMBRAPA trabaja directamente relacionado con ellos. El Centro Nacional de Pesquisa de Uva e Vinho (CNPUV) de EMBRAPA, situada en Bento Goncalves tiene como misión generar y promover conocimiento y tecnología para el desarrollo sustentable del complejo agroindustrial vitivinícola nacional. Según datos de Embrapa 2007, la producción de vinos en Brasil con IG es de 1,3 millones de litros.

Las indicaciones geográficas presentes en la región son (Tabla 1):

TABLA 1. INDICACIONES GEOGRÁFICAS EN SERRA GAUCHA

\begin{tabular}{|c|c|c|c|c|c|}
\hline Nombre IG & Entidad & $\mathrm{N}^{\circ}$ Vinícolas & Área & Ubicación & IG \\
\hline $\begin{array}{l}\text { Vale dos } \\
\text { Vinhedos }\end{array}$ & $\begin{array}{l}\text { APROVA- } \\
\text { LE }\end{array}$ & $\begin{array}{c}31 \\
\text { (5 con indicación) }\end{array}$ & $\begin{array}{l}8123 \mathrm{~km}^{2} \\
2123 \text { ha } \\
\text { vitic. }\end{array}$ & $\begin{array}{l}\text { Serra Gaú- } \\
\text { cha }\end{array}$ & $\begin{array}{l}\text { IPVV } \\
(2001)\end{array}$ \\
\hline $\begin{array}{l}\text { Vinhedos } \\
\text { de Monte } \\
\text { Belo }\end{array}$ & $\begin{array}{l}\text { APROBE- } \\
\text { LO }\end{array}$ & 11 & 2300 has & $\begin{array}{l}\text { Serra Gaú- } \\
\text { cha }\end{array}$ & Proyecto \\
\hline $\begin{array}{l}\text { Vinhos } \\
\text { dos Altos } \\
\text { Montes }\end{array}$ & $\begin{array}{c}\text { APRO- } \\
\text { MONTES }\end{array}$ & $\begin{array}{c}11 \\
\text { (1 con indicación) }\end{array}$ & & $\begin{array}{l}\text { Serra Gaú- } \\
\text { cha/ Flores } \\
\text { da Cunha }\end{array}$ & Proyecto \\
\hline $\begin{array}{l}\text { Vinhos de } \\
\text { Montanha }\end{array}$ & & $\begin{array}{l}6 \text { (2 con indica- } \\
\text { ción) }\end{array}$ & & $\begin{array}{l}\text { Serra Gau- } \\
\text { cha }\end{array}$ & \\
\hline
\end{tabular}

Fuente: Elaboración propia.

El área geográfica IP Vale Dos Vinhedos se localiza en los municipios de Bento Goncalves, Garibaldi y Monte Belo do Sul, Serra Gaúcha en el estado de Rio Grande Do Sul. Vale Dos Vinhedos produce el 20\% de los vinos finos y el 35\% de los espumantes de Rio Grande Do Sul. A continuación (Tabla 2) es posible observar la evolución en la producción en botellas, así como la cantidad producida con indicación de procedencia, la cual ha disminuido en el período bajo análisis. 
TABLA 2. ELABORACIÓN DE VINOS CON INDICACIÓN DE PROCEDENCIA EN VALE DOS VINHEDOS

\begin{tabular}{|c|c|c|c|}
\hline Años & $\begin{array}{l}\text { Vino fino elaborado }\left(\mathrm{N}^{\circ} \text { bo- }\right. \\
\text { tellas) }\end{array}$ & Vino fino con IP ( $\mathrm{N}^{\circ}$ sellos $)$ & $\%$ vino con IP \\
\hline 2001 & 6.621.248 botellas & 1.574 .897 & 23,78 \\
\hline 2002 & 7.416.170 botellas & 2.120 .973 & 28,59 \\
\hline 2003 & 10.249.490 botellas & 1.943 .525 & 18,96 \\
\hline 2004 & 12.478.149 botellas & 2.349 .333 & 18,82 \\
\hline 2005 & 12.852 .373 botellas & 2.329 .353 & 18,12 \\
\hline 2006 & 9.170.196 botellas & 1.757 .858 & 19,16 \\
\hline 2007 & 9.985 .780 botellas & 1.652 .667 & 16,50 \\
\hline
\end{tabular}

Fuente: Elaboración propia sobre la base de Tonietto (2003), EMBRAPA uva e vinho.

Según APROVALE (2005) ya se observan una serie de cambios en la región de influencia de la IG y en el perfil de las vinícolas, dentro de los cuales se destacan:

Cambios en las áreas geográficas de producción: incremento del valor de la propiedad del productor, estímulo a las inversiones en la propia zona de producción (nuevas plantaciones, mejoras tecnológicas en el campo y la agroindustria de vino, mayor participación del productor en el ciclo de comercialización de los productos, incentivos a las mejoras tecnológicas.

Cambios en el mercado: aumenta el valor agregado de los productos, genera mayor facilidad en la colocación en el mercado, mejoras en la demanda del producto.

Asimismo, Tonietto (1992) establece que las IG tienen potencial para generar un conjunto de cambios capaces de dar soporte al desarrollo de la vitivinicultura. A las ya mencionadas ventajas agrega una mayor satisfacción del productor que ve sus productos comercializados con IG que corresponde a su local de trabajo; estimula la mejora cualitativa de los productos ya que los mismos están sometidos a los controles de producción y de elaboración; contribuye para la preservación de las características y de la tipicidad de los productos que se constituyen en un patrimonio de cada región/país; posibilita incrementar las actividades de enoturismo. Desde el punto de vista mercadológico, mejora y torna más estable la demanda del producto, al crear confianza al consumidor que atribuye confianza a la calidad del producto a partir de la IG. Permite igualmente al consumidor identificar perfectamente entre los productos. Desde el punto de vista de la protección local, genera mecanismos legales contra fraudes y usurpaciones, facilitando la acción contra el uso indebido de la IG. 


\subsection{Mendoza}

En Mendoza, la estrategia de las "indicaciones geográficas" es reciente. Empieza a considerarse en la década de los ochenta como una de las vías para incorporarse al mercado mundial, frente a un mercado interno saturado. Pero solamente un área vitivinícola, con una producción de calidad reconocida, adoptó para diferenciar su vino en el comercio una denominación muy amplia que se conoce como "Primera Zona".

La inserción en los mercados internacionales generó una notable innovación en la Vitivinicultura Argentina, motivada principalmente por la necesidad de adecuarse a las nuevas exigencias de los mercados importadores. Todo este proceso de cambios estructurales ha sido acompañado con la Ley 25.163 - Decreto Reglamentario 57/2004 sobre Indicaciones de Procedencia, Indicaciones Geográficas y Denominaciones de Origen Controladas para Vinos y Bebidas Espirituosas de origen vínico. En la provincia de Mendoza podemos hallar las siguientes IG en la tabla 3.

Las indicaciones geográficas implican en Argentina que existen zonas donde los productores se han comprometido a cultivar y cosechar las uvas bajo determinadas pautas que mejoran su calidad, articulando además controles confiables que garantizan el acatamiento a tales pautas. Dichas pautas determinan que los vinos D.O.C. deben provenir de uvas autorizadas exclusivamente por sus Consejos; que la vinificación se realice conforme al reglamento; que la crianza en Roble de un vino no puede ser inferior a 8 meses y el período de guarda en botella no debe ser inferior a 12 meses. Un Vino D.O.C. es ante todo un vino de calidad superior, que responde a una personalidad distintiva del terruño del cual proviene. Las zonas con D.O.C. en Argentina son por el momento dos, Luján de Cuyo (provincia de Mendoza) y San Rafael (Sur de provincia de Mendoza). En Luján de Cuyo se inició el tema D.O.C. en 1987, donde representantes de diez bodegas conforman el Consejo de Denominación de Origen. Según datos del INV se han declarado 6098,52 hectolitros de vinos de cepa Malbec con Indicación Geográfica y 25277,79 hectolitros con Indicación de Procedencia.

\section{TABLA 3. INDICACIONES GEOGRÁFICAS DE MENDOZA}

\begin{tabular}{cc}
\hline Denominación & Departamentos de Mendoza \\
\hline Agrelo & Luján de Cuyo \\
Barrancas & Maipú \\
El Paraíso & Maipú \\
General Alvear & Mendoza \\
Godoy Cruz & Mendoza \\
Guaymallén & Mendoza \\
Junín & Mendoza \\
La Paz & Mendoza
\end{tabular}


TABLA 3 (continuación). INDICACIONES GEOGRÁFICAS DE MENDOZA

\begin{tabular}{cc}
\hline Las Compuertas & Luján de Cuyo \\
Las Heras & Mendoza \\
Lavalle & Mendoza \\
Luján de Cuyo & Mendoza \\
Mendoza & Mendoza \\
Maipú & Mendoza \\
Rivadavia & Mendoza \\
Russel & Maipú \\
San Carlos & Mendoza \\
San Martín & Mendoza \\
San Rafael & Mendoza \\
Santa Rosa & Mendoza \\
Tunuyán & Mendoza \\
Tupungato & Mendoza \\
Valle de Uco & Departamento de San Carlos, Tunuyán y Tupungato \\
\hline
\end{tabular}

Fuente: Elaboración propia según datos del INV.

De todas las provincias, la indicación geográfica de los vinos más utilizada fue Mendoza (70,54\%), le sigue en orden de Valle de Cafayate (Salta). Actualmente, estas denominaciones no tienen el resultado esperado en Argentina debido a que los consumidores, internos o externos, no realizan una marcada diferenciación de estos productos por sobre otros; así como tampoco las bodegas logran posicionar mejor esta gama de productos.

GRÁFICO 4. CONSUMO DE VINO VARIEDAD MALBEC SEGÚN TIPO IG

Despachos al consumo de vinos varietales Variedad Malbec - Año 2009 -\% hectolitros

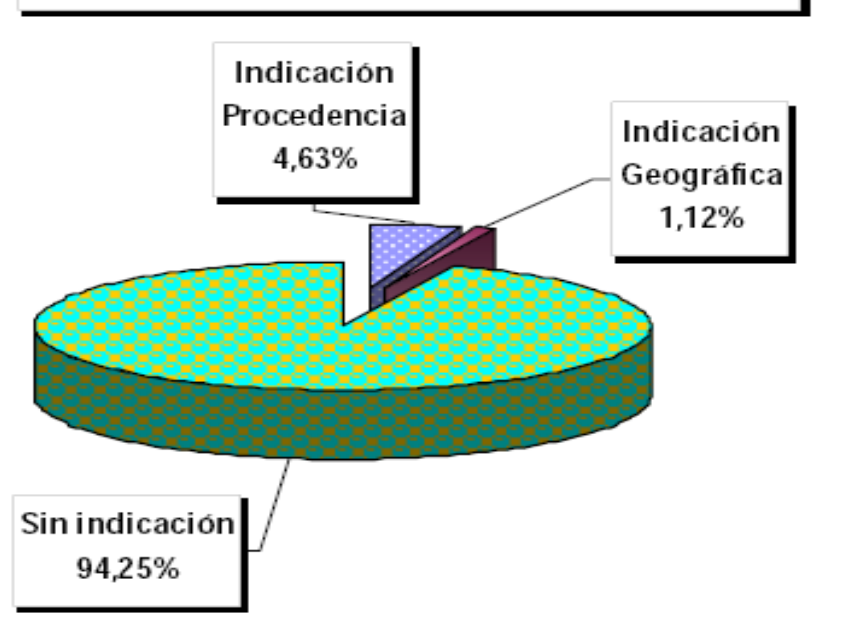

Fuente: INV, 2009. 


\section{Correlación entre el desarrollo productivo del cluster y el desarrollo local}

Alderete y Bacic (2011) realizan un estudio que identifica la presencia de una tendencia virtuosa de la actividad del cluster vitivinícola de Mendoza con los indicadores económicos y socio-demográficos de la provincia. Mediante un análisis de correlación, la tendencia económica virtuosa del cluster vitivinícola es seguida por una tendencia en igual dirección en los aspectos sociales,

Siguiendo los lineamientos de los autores, se realizó un agrupamiento de los diferentes indicadores de la actividad vitivinícola en Rio Grande Do Sul: Comercialización de vinos en el mercado externo (en litros) de Brasil; Importaciones de uva fresca; Producción de vinos de mesa en litros; Producción de vinos de viníferas en litros; Producción de mosto; Producción de uva vinífera, Comercialización de vino de mesa en litros; Comercialización de vino de viníferas en litros; Exportaciones de vinos de mesa; Comercialización de vinos en el mercado interno (Brasil). Se construye sobre la base de estas variables un factor o indicador mediante un análisis factorial.

TABLA 4

\begin{tabular}{c|c|c|c|c|c|c}
\hline \multirow{2}{*}{ Componente } & \multicolumn{3}{|c|}{ Autovalores iniciales } & \multicolumn{2}{c}{$\begin{array}{c}\text { Sumas de las saturaciones al } \\
\text { cuadrado de la extracción }\end{array}$} \\
\cline { 2 - 7 } & Total & $\begin{array}{c}\text { \% de la va- } \\
\text { rianza }\end{array}$ & $\begin{array}{c}\text { \% acumu- } \\
\text { lado }\end{array}$ & Total & $\begin{array}{c}\% \text { de la } \\
\text { varianza }\end{array}$ & $\begin{array}{c}\% \text { acu- } \\
\text { mulado }\end{array}$ \\
\hline 1 & 6,553 & 59,576 & 59,576 & 6,553 & 59,576 & 59,576 \\
2 & 3,492 & 31,750 & 91,326 & 3,492 & 31,750 & 91,326 \\
3 &, 637 & 5,795 & 97,121 & & & \\
\hline
\end{tabular}

Fuente: Elaboración propia mediante SPSS.

Es posible observar los autovalores o valores propios conocidos también como eigenvalues. Estos se encuentran en la columna total para cada componente (para el componente 1 el autovalor es 6,553 y para el componente 2 es 3,492. En la siguiente columna se observa el porcentaje de varianza explicada con el método de extracción. Por lo tanto, con la técnica de análisis factorial pasamos de 11 variables observables a dos variables ficticias:

ICV: Indice de comercialización vitivinícola.

IPV: Indice de producción vitivinícola.

Con los cuales se explica el $91,32 \%$ de la varianza total.

La matriz de componentes contiene las proyecciones de cada una de las variables sobre cada uno de los factores encontrados mediante el método de com- 
ponentes principales, estas proyecciones reciben el nombre de saturaciones.

A continuación se plantea un análisis de correlación entre el Indice de Desenvolvimento Socioeconómico (IDESE) y los indicadores hallados con el análisis factorial. El IDESE es un índice publicado por la Fundación de Economía y Estadística del Estado de Rio Grande Do Sul. Se trata de un índice sintético inspirado en el IDH e incluye una serie de indicadores económicos y sociales (12), tales como educación, ingreso, saneamiento y domicilios, salud ${ }^{3}$. Su objetivo consiste en medir y acompañar el nivel de desarrollo del Estado. Varía de o a 1 y de acuerdo a los datos disponibles para el periodo analizado (1993-2008) presenta un nivel medio.

\section{TABLA 5. MATRIZ DE COMPONENTES}

\begin{tabular}{l|c|c}
\hline & \multicolumn{2}{|c}{ Componente } \\
\cline { 2 - 3 } & ICV & IPV \\
\hline Comercialización vino mercado externo (litros) Brasil &,- 962 &, 178 \\
Importaciones uva fresca &,- 902 &,- 031 \\
Producción de vino de mesa en litros &, 337 &, 732 \\
Producción de vino de viníferas en litros &, 085 &, 979 \\
Producción de mosto &, 862 &, 130 \\
Producción uva vinífera &, 277 &, 949 \\
Comercialización vino de mesa en litros &, 987 &, 001 \\
Comercialización vino fino en litros &,- 636 &, 512 \\
Exportaciones vino de mesa &,- 869 &, 483 \\
Comercialización vino mercado interno (litros) Brasil &, 895 &, 203 \\
\hline
\end{tabular}

Fuente: Elaboración propia mediante SPSS. Método de extracción: Análisis de componentes principales. a 2 componentes extraídos

TABLA 6. MATRIZ DE CORRELACIONES

\begin{tabular}{|c|c|c|c|c|}
\hline & & IDESE & ICV & IPV \\
\hline \multirow[t]{3}{*}{ IDESE } & Correlación de Pearson & 1 & ,724 &,- 397 \\
\hline & Sig. (bilateral) & . & , 166 &, 508 \\
\hline & $\mathrm{N}$ & 9 & 5 & 5 \\
\hline \multirow[t]{3}{*}{ ICV } & Correlación de Pearson & ,724 & 1 & , ooo \\
\hline & Sig. (bilateral) & , 166 & . & 1,000 \\
\hline & $\mathrm{N}$ & 5 & 7 & 7 \\
\hline \multirow[t]{3}{*}{ IPV } & Correlación de Pearson &,- 397 & ,ooo & 1 \\
\hline & Sig. (bilateral) &, 508 & 1,000 & . \\
\hline & $\mathrm{N}$ & 5 & 7 & 7 \\
\hline
\end{tabular}

Fuente: Elaboración propia.

3 Para mayor información sobre la metodología aplicada para la construcción del IDESE visitar el sitioweb www.fee.tche.br 
A partir de los datos obtenidos, se observa la falta de correlación entre los indicadores del sector vitivinícola y el indicador del IDESE. Este resultado contrasta con el obtenido en el caso Mendocino.

\section{Consideraciones finales}

Este trabajo utiliza el marco teórico del desarrollo local en un primer intento por analizar los clusters vitivinícolas de Mendoza (Argentina) y Serra Gaúcha (Brasil). El cluster vitivinícola mendocino por su desempeño destacable durante los últimos años reflejado en la creciente tendencia exportadora; y el de Serra Gaucha, por ser el polo vitivinícola más destacado de Brasil, que junto con Argentina son los países más importantes del MERCOSUR.

En Mendoza, la reconversión productiva ha sido un proceso importante para el avance de la industria vitivinícola. La creciente internacionalización del sector vinícola se manifiesta en el aumento de la producción y el consumo de vinos varietales, en detrimento de vinos comunes y en el fuerte aumento de las exportaciones. Una estrategia que acompaña esta tendencia ha sido la definición de indicaciones geográficas en varias regiones productivas.

La definición de indicaciones geográficas se constituye en una estrategia que puede generar el aumento de competitividad de los productos producidos en el territorio local, promoviendo su desarrollo local. La modernización de los viñedos tradicionales de RGS en respuesta a las exigencias y oportunidades del mercado es un objetivo primordial. Este es un camino necesario en la búsqueda de nuevas indicaciones geográficas.

Si bien los dos países producen vino, lo realizan con un enfoque diferente, ya que los vinos producidos en Mendoza tienen demanda externa mayor que los vinos producidos en Rio Grande do Sul. Para determinar la relación entre el desempeño del sector vitivinícola y el desarrollo socioeconómico de la región de Rio Grande Do Sul, se procedió en primer lugar a hallar dos indicadores del sector vitivinícola mediante un análisis factorial. La falta de una correlación significativa de los indicadores de producción y comercialización vitivinícola con el IDESE (Índice de Desarrollo Socio-Económico), sugieren que el avance del sector vitivinícola aún no es acompañado por una tendencia de igual magnitud en el aspecto socio-económico. Este resultado contrasta con el hallado para la región mendocina. Una posible explicación radica en que todavía las exportaciones son bajas. Esta evidencia cuantitativa por sí misma es débil para explicar el mejor desempeño económico del sector. Es de importancia cuando se combina con indicadores cualitativos tales como la reestructuración de los 90; orientación estratégica predominantemente hacia el crecimiento, esfuerzos concertados hacia el aumento de la calidad (con la promoción de las indicaciones geográficas), apoyo institucional y consorcios de exportación. Lamentablemente no se dispone de información vitivinícola 
a nivel municipal en Brasil, por lo cual la delimitación del área geográfico de los indicadores vitivinícolas podría mejorarse si ésta estuviera disponible, y mayor sería el vínculo de estos indicadores con las indicaciones geográficas.

\section{Referencias}

ALLAIRE, G.; SYLVANDER, B. (1997). Qualité spécifique et systèmes d'innovation territoriale. Cahiers d'Economie et Sociologie Rurales, n. 44.

ALDERETE, M.V Y.; BACIC, M.J. (2011). El cluster vitivinícola mendocino: una aproximación desde la teoría del desarrollo territorial. Memorias del 2 Congreso Internacional sobre la MIPYME en México. Guadalajara : Universidad del Valle de Atemajac, , 7-9 de Septiembre de 2011, v. 1. p. 1-25.

BÉRARD, L.; MARCHENAY, P. (2008). From Localized Products to Geographical Indications: Awareness and Action. CNRS.

BOSCHERINI,F. y POMA, L. Territorio, conocimiento y competitividad de las empresas: El rol de las instituciones en el espacio global. Miño y Dávila editores, 2000.

CARAVACA, I; GONZALEZ, G., SILVA, R. (2005). Innovación, redes, recursos patrimoniales y desarrollo territorial. Revista Eure, Vol. XXXI, No 94, pp. 5-24, Santiago de Chile.

CASSIOLATO, J. E., LASTRES, H. M. M. (2003). “O Foco em Arranjos Produtivos Locais de Micro e Pequenas Empresas”. In LASTRES, M. H. H., CASSIOLATO, J. E., MACIEL, M. L. Pequena Empresa: Cooperação e Desenvolvimento Local. Rio de Janeiro: Belume Dumará \& Instituto de Economia da UFRJ.

CAVESTANY, F. (2000). Desarrollo desde el territorio. A propósito del desarrollo local. Unidad de Fortalecimiento de los Gobiernos Locales de la Universidad Nacional de Quilmes y la Hanns Seidel Stiftung e.V.. Buenos Aires. Disponible en la Biblioteca Digital Municipal http://biblioteca.municipios.unq.edu.ar/ modules/mislibros/archivos/Barreiro.pdf

CERDAN, C.; VITROLLES, D. (2008). Valorisation des produits d'origine: contribution pour penser le développement durable dans la Pampa Gaúcha au Brésil. Géocarrefour, v. 83, n. 3 .

CORÓ, G. Cap.9: Contingencia, aprendizaje y evolución en los sistemas productivos locales. (2000). En Boscherini, F. y Poma, L. Territorio, conocimiento y competitividad de las empresas: el rol de las instituciones en el espacio global. Miño y Dávila Editores, En Buenos Aires, Septiembre.

FENSTERSEIFER, J. (2006). “The emerging brazilian wine industry: challenges and prospects for the Serra Gaúcha wine cluster." $3^{\text {rd }}$ international wine business research conference, Montpellier, 6-7 july.

GALLICCHIO, E. (2004). El desarrollo local en América Latina. Estrategia política basada en la construcción de capital social. Seminario "Desarrollo con inclusión y equidad: sus implicancias desde lo Local”, SEHAS, Córdoba (Argentina).

GAROFOLI, G. (1995). Desarrollo económico, organización de la producción y territorio. En: Vázquez Barquero, A. Y Garofoli, G. (editores). Desarrollo Económico Local en Europa, Colegio de Economistas de Madrid, Madrid, 53-71. 
GOLLO, S. S. (2006). “Delineamento e aplicação de Framework para análise das inovações numa perspectiva de processo interativo: estudo de caso da indicação de procedência vale dos vinhedos - Serra Gaúcha/RS.” Teoria e Evidência Econômica, v. 14.

IIRSA (2006). "Estudo de avaliação do potencial de integração produtiva dos eixos de integração e desenvolvimento da iniciativa IIRSA. Informe final. Parte C. Capítulo VII. Iniciativa para a Integração Regional Sul-Americana (IIRSA). Disponible en www.iirsa.org/BancoMedios/Documentos\%20PDF/plan_ip_parte_c8.pdf

LEMOS JEZIORNY, D. (2009). “Território Vale Dos Vinhedos. Instituições, Indicação Geográfica e Singularidade na Vitivinicultura da Serra Gaúcha.” Tesis para maestria em Economía, Universidade Federal de Uberlândia.

NARVÁEZ, M., FERNÁNDEZ, G., SENIOR, A. (2008). El desarrollo local sobre la base de la asociatividad empresarial: una propuesta estratégica, Opción, Año 24, No. 57, pp. $74-92$

NIEROP, M. (2010). “The evolution of the Brazilian wine industry.” Tesis Universiteit Utrecht y Universidade Do Vale Do Rio Dos Sinos.

NIEDERLE, P.A, y VITROLLES, D. (2010). Indicações Geográficas e qualificação no setor vitivinícola brasileiro. Estud. Soc. e Agric., Rio de Janeiro, vol. 18, n. 1 , pp 5-55.

PADILLA COBOS, E. (1996). “Teoría territorial: entre totalización y fragmentación”, en Ciudades, núm. 29, RNIU,México, pp. 17-20.

REIS, J. Ensaios de economia impura. Coimbra: Edições Almedina, 2007.

TONIETTO, J. (2002). “Indicação geográfica Vale dos Vinhedos: sinal de qualidade inovador na produção de vinhos brasileiros.” In: V Simpósio Latino-Americano Sobre Investigação E Extensão Em Pesquisa Agropecuária/V Encontro Da Sociedade Brasileira De Sistemas De Produção, Florianópolis.

VANDECANDELAERE, E.; ARFINI, F.; BELLETI, G.; MARESCHOTTI, A. (2009). "Linking people, places and products." FAO, Sinergi: Roma.

VÁZQUEZ BARQUERO, A. (1998). Desarrollo endógeno. Conceptualización de la dinámica de las economías urbanas y regionales. En: Cuadernos del Cendes, $\mathrm{N}^{\mathrm{O}}(38)$, pp. $45^{-65}$.

VÁZQUEZ BARQUERO, A. Política Económica Local, Ed. Pirámide. Madrid, 1986.

\section{Sitios web consultados:}

APROVALE. Relatórios do Conselho Regular da Indicação de Procedência Vale dos Vinhedos, 2001 a 2005.

DEIE, Dirección de Estadísticas e Investigaciones Económicas. Gobierno de la Provincia de Mendoza, http://www.deie.mendoza.gov.ar/

EMBRAPA UVA E VINHO, http://www.cnpuv.embrapa.br/

IBGE, Instituto Brasileiro de Geografía y Estadística, http://www.ibge.gov.br/ espanhol/

INV, Instituto Nacional de Vitivinicultura. www.inv.gov.ar

IBRAVIN, Instituto Brasileiro do Vinho 
ALDERETE, M. V. La influencia del cluster vitivinícola en el desarrollo local....

Recebido em: 31 de agosto de 2012 Aceito em : 24 de maio de 2013 